\title{
The Economic Impact of Regional Financial Diversity Development in China
}

\author{
Yishen Feng \\ Institute of Economics and Management \\ Tianjin University of Technology and Education \\ Tianjin, China 300222
}

\author{
Xuexin Wang \\ Institute of Economics and Management \\ Tianjin University of Technology and Education \\ Tianjin, China 300222
}

\begin{abstract}
Based on the 7th, CDI CFCI research report and 2014 China's regional financial operation report, Analysis of the current tend to be more severe domestic and international economic environment, financial resources to national financial center agglomeration "Matthew effect" is more remarkable. China's financial centre accelerated development, contrarian expansion development momentum. China's regional financial development presents the tendency of imbalance, besides, the difference of the regional financial phenomenon is more obvious. The financial industry in the face of the huge development opportunity at the same time also is faced with severe challenges. Putting forward the appropriate financial gap for promoting regional competition is also good, we can control the financial gap to a certain level, using their own conditions for economic development, making full use of the geographical advantage, economic development, spatial dependence, financial cooperation and other geographical conditions. By way of strengthening regional exchanges, playing the role of regional financial center effectively, expanding the scope of financial diffusion and intensity, and reducing the gap of regional financial development to realize sustainable development in financial industry.
\end{abstract}

Keywords-regional financial; differences; development; economy; impact

\section{INTRODUCTION}

A country's financial development level directly affects the economic growth ability, the level of financial development in different areas and has a direct contribution to the development of regional economy. Financial resource is the core of the modern market economy, the financial development level has become the key factor to promote the growth of regional economy, the development of regional economy has important strategic significance. In recent years, our country speeds up the strategic layout of the regional economic development. Throughout all the country's economic area of strategic planning, one of the most significant common characteristics is to enhance the level of regional financial development as an important strategic choice, through regional financial agglomeration, give full play to the growth of the financial effect and radiation effect, to financial development promote industrial structure adjustment and change of the pattern of economic growth, to realize the sustainable development of regional economy.
On September 23, 2015, Comprehensive development institute (shenzhen), China released the 7 th period of "China's financial centre index" report (CDI CFCI), Shanghai, Beijing, shenzhen are still the top three. The index to multi-dimension, integrated measure of development in China's financial centre, the objective evaluation of performance of 31 financial center cities in China in the financial industry, financial institutions, financial market scale and the achievements of the financial ecological environment and the insufficiency. 7th, CDI CFCI, comprehensive competitiveness of China's financial centre of the top 10, in turn, are: Shanghai, Beijing, shenzhen, guangzhou, tianjin, chengdu, hangzhou, chongqing, nanjing, suzhou, dalian, wuhan, xi 'an. According to the seventh stage of CDI, CFCI's research shows that the development of Chinese financial center appears a series of new features:

First, in the severe domestic and international economic environment, to China's financial centre accelerated development, contrarian expansion development momentum. Comprehensive competitiveness of China's financial centre average score increased from previous 36.11 points to 41.30 points, the rise of $14.4 \%$, in the third phase of CDI, CFCI index is the highest since the release. 31 the added value of China's financial center finance combined values increase from the previous 1.91 trillion yuan to 2.91 trillion yuan, the growth of $15 \%$, far higher than the same period of 31 Chinese financial center city year-on-year growth of GDP, the added value of 31 financial center of China financial industry the proportion of GDP accounted for city average of $8.7 \%$, according to the financial sector and financial center construction to further improve the position in national economy.

Second, the financial resource to national financial center agglomeration "Matthew effect" is all the more remarkable. Three financial centers in China are Shanghai, Beijing and shenzhen. They aim at maintaining the absolute leading position, and trend of present advantages to expand.

Third, the regional financial center "layers" development pattern tends to be stable. And three national financial center, long-term "monopoly" CDI CFCI index, the top three, in the seventh period, CDI CFCI, guangzhou, tianjin, chengdu, hangzhou, chongqing, nanjing, suzhou, dalian, wuhan and xi 'an is the regional financial center top 10 , including tianjin, dalian, hangzhou, guangzhou, wuhan and chengdu are still in 
the northern coastal region, northeast region, eastern coastal region, the southern coastal area, the central region and western region of the regional financial center in the respective keep ahead.

Fourth, China's six big economic zones diversified regional financial center competition situation. The northern coastal area of tianjin lead expands unceasingly, in the center of the regional and even national financial competition; Eastern coastal areas of hangzhou, nanjing and suzhou go hand in hand, the national top ten; Southern coastal regional financial center development speed lags behind the average level, in the leading position in the national regional financial center in guangzhou relative weakening; Competitiveness overall weak northeast regional financial center, has failed to enter the national top ten financial center; Wuhan in central China, Zhengzhou, changsha competitiveness gap, regional financial center competition pattern is unclear; In the western region in chengdu and chongqing double leading regional financial center development, respectively ranked the sixth and eighth nationwide.

\section{REGIONAL FINANCIAL DIFFERENCE}

According to the 7th report "China's financial centre index" (CDI CFCI), according to a study by the development of Chinese financial center appears a series of new features. At present, the financial industry in the face of the huge development opportunity at the same time also is facing serious challenges. China's regional financial development shows the tendency of imbalance. Since China's reform and opening up, along with the development of the economic system reform, greatly promote the economic development of China's eastern coastal areas, but distinct regional economic development strategy is to make our economy run unbalanced phenomenon is more obvious, which lead to the difference of the regional financial phenomenon is more obvious, whether between provinces and autonomous regions, or inside the province, there are many differences between both.

According to the regional financial operation report "of 2014, 2014, the overall economic growth in China in the river range, structural adjustment of present positive changes. Urban and rural residents income gap narrowed, continue to improve the added value of the third industry. At the same time, the contribution of consumption to economic growth has increased. Regional development more coordinated and balanced, the eastern region economy has good elasticity, relatively stable operation, strategic emerging industry, service industry develops rapidly, and steady progress was made in industrial transformation and upgrading; The Midwest undertake accelerated urbanization and industry, maintaining rapid economic development; Northeast agriculture as the foundation is relatively stable, but the economic structural adjustment and transformation of pressure. In 2014, respectively in eastern, central, western and northeast region's GDP totaled 35.0 trillion yuan, 13.9 trillion yuan, 13.8 trillion yuan and 5.7 trillion yuan, the area proportion of GDP, the eastern region accounted for $51.2 \%$, the central region accounted for $20.3 \%$, in the western region accounted for $20.2 \%$, the northeast area accounted for
8.4\%.Due to the economic growth rate is higher than other areas in western China, the rise in GDP accounted for 11 consecutive years, the cumulative increase of $3.3 \%$. However, in the total assets of financial institutions in our country, the eastern region accounted for $58.4 \%$, was $1.8 \%$ lower than in 2011; Central, western and northeast China the sum of $41.6 \%$, are up $1.6 \%$ on 2011. Bank employees accounted for, the eastern region accounted for $45.2 \%$, accounted for $20.3 \%$ of central, the west accounted for $23.8 \%$, The northeast accounted for $10.7 \%$, northeast east bank workers, a $1.5 \%$ increase from 2011. The central, west, northeast bank employees have different degrees of lower. Thus, the eastern region offers the most financial resources in China, and some of the less developed region is money supply. From the point of the zone distribution of stock market value, the distribution of Chinese stock market is the phenomenon of the "east west high low. Being the absolute scale of value of shares or relative size, the eastern region is much higher than the Midwest, especially in recent years, the eastern region of the proportion of the total market value of the shares also shows a tendency of increase year by year.

Therefore, regional financial development difference is too big, not only exacerbate differences in regional economic development, and made the financial policy in different regions between the effect of a huge contrast, our country is a developing country is in transition period, the emphasis on the study of the regional financial difference is very important for the current economic situation.

\section{THE CAUSE OF REGIONAL FINANCIAL DEVELOPMENT DIFFERENCE ANALYSIS AND THE IMPACT ON THE ECONOMY}

\section{A. The Difference in the Degree of Economic and Social Development}

Finance as the core of modern economy, the economic and social development plays a very important role, the degree of economic development determines the financial development level. At the same time, the adverse effect of financial development to economic growth is also very obvious, reaction including positive and negative effects. In terms of area, the same broad economic and financial relationship, the regional economy is the objective foundation of regional financial existence and development, regional economic development level of high and low, speed of growth, growth mode and efficiency etc., also a direct impact on the development of regional finance. Therefore, based on the regional economy and regional finance such a relationship, it can be said that the existence of regional financial development difference, the most direct reason lies in the different regional economic development level.

A kind of balance will be a fundamental influence on the development of the regional financial. Area population quality, the education degree of different, for example, in the financial products and financial innovation adoption is different; Some regional financial development, especially the folk financial development has a long history, has formed a certain scale, but some late, slow regional financial development, the intangible, constitutes the spatial difference of regional financial development. 


\section{B. Geographical Space Distribution Disequilibrium}

Both from natural geographical location, natural conditions and natural resources, China's four big plate (eastern, central, northwest, northeast) is quite different, and provincial differences are very obvious. Any human activity is dependent on the specific natural geographical location, and different geographical conditions and different degrees of influence on human social activity, the eastern coastal area, with its advantageous geographical location, in attracting talent and has obvious advantages in capital, cost reduction, etc. soil fertility level factor and other natural conditions, regional planning, industrial spatial layout, policy making, and even money flowing into the basic problems such as the basis. The fickle kinds of funds and make more money inflows has good natural conditions, the high efficiency of investment area, this directly lead to different natural conditions region difference of financial development. Natural resources is the source of human survival, also essential prerequisites to regional development, natural resource abundance or not, all kinds of industry in the local has a close relationship with the concentration degree and the scale of high and low, in the development of the financial sector, especially the regional financial structure is also restricted by regional distribution of natural resources.

\section{The Unity of the Financial Policy}

Planned economy era of "unified" the financial system, although the country can control of national fiscal and financial resources, and facilitate the development of the basic construction project. With the development of market economy, but this form early is not fit for the requirement of modern financial development, to some extent, restricted the regional economic growth. Nowaways, in market economy development, this "one size fits all" type of financial in many areas in China there are still a lot of the impact of the development of financial markets. And nationally, the height of the financial macro-control policy of unity each region's ability to withstand, application and digest the government's policy is different. Main channels of funding sources in less developed areas or bank credit, and poor adaptability to the country's macroeconomic regulation and control, is not conducive to the development of financial markets; And the developed region in all aspects of the financial advantage, make it more flexible in the face of national policy. Moreover, monetary policy is "the rope effect", namely the backward area more sensitive in tightening policy, and developed regions are more sensitive for expansion, the existence of such an effect, makes the monetary policy effects vary between different regions. Can be thought of in our country, therefore, a unified financial policy is also one of the important reasons for the regional financial development difference.

\section{Unbalanced Regional Economic Development Strategy}

Since the founding of the people's regional development strategy in our country has experienced several stages. Shortly after the founding of new China, leaning to the "three line" region of the regional strategy, laid the foundation of the Midwest industrial development of our country, but also makes the region formed on the basis of the heavy industry industrial structure, so a kind of industrial structure to a certain extent, restrict regional finance, and even the development of the tertiary industry. After the third plenary session, Tilt to the coastal areas of regional development strategy implemented, a lot of fiscal, tax, credit and other aspects of the preferential policies began in the eastern region, but at the same time, the opening to the outside world and the reform of economic system in the east also try first. The middle 1990s, although regional development strategy in our country started to pay more attention to regional coordinated development, in order to narrow the gap in development among regions, but the financial arrangements between regions is still lack of fair and reasonable. Although the government has to get rid of the traditional direct control, but still a lot of resources in the hands of the local government, and a number of financial development as a whole have not been effectively implement policies and measures, leading to regional differences of financial development.

From the above analysis, although our country has entered the stage of regional coordinated development, but the effect not beautiful in coordination of regional financial development, even has the tendency of further widening regional disparities, coupled with the unbalanced development strategy of regional financial development in the history of the impact of, these should be a macro cause of the difference of regional financial development in our country the financial system at the present stage in China, is the banking industry as the leading financial system. As a result, Banks play a core role in financial and promoting economic growth in the process of play a vital role.

\section{E. The Local Government on the Financial Intervention}

Before the financial system reform, the local government intervention and control of local financial development desire is not strong. After the decentralization reform, for the purpose of the performance evaluation of local government, for the thousands of advancement in the field of economy and finance having become increasingly apparent. Place in the financial aspects of the competition is competition for financial resources. On the one hand, the development of the financial institutions plays a decisive role to offer more financial resources. As a result, many local governments based on the practice areas, vigorously developing regional financial institutions. Series of local joint-stock commercial Banks, such as GDB, deep issue, pudong development bank, etc. Along with the development of the regional bank, a large number of branches and outlets have been all over the country, to accelerate regional economic development at the same time, also absorbed from the financial resources from all over the country .On the other hand, access to financial resources, need with the central government "bargain". In this way, also requires the local government on financial resources allocation problem ability is limited. Therefore, developed areas and the bargaining power of the government at a higher level is higher than less developed areas. Visible, local government intervention of local financial development and its influence the size of the financial, directly affects the 
region's ability to obtain financial resources, thus affecting the level of regional financial development.

\section{F. Differences of Financial Awareness}

The perfect degree of the district people's financial awareness directly related to the level of regional financial development and prospect. Financial awareness by different local culture, religion, custom, and the regional economic and financial development phases, and so on various aspects, the influence of its formation is a long-term process. Specifically, the perfect financial consciousness should include the cognition of modern financial ability, innovation ability and application ability. Cognitive ability including the traditional and the modern financial system, financial system and financial products and the understanding, understanding and accept ability; Innovation ability is mainly in terms of financial instruments, and adapt to the different stages of economic development needs and its financial tools, the traditional financial instruments cannot adapt to the modern economic development, the innovation of financial tools is important; Application ability can easily understand in order to adapt to economic and social development of the financial awareness of popularity, the district market structure, the maturity and related policy has a direct relationship.

\section{COUNTERMEASURES AND SUGGESTIONS}

The existence of China's regional financial development difference is objective, but the objective existence of difference to get effective control. From the perspective of the analysis of this article, first of all, to reduce regional differences in the development of banking, the key is to take effective measures to narrow the differences in the group, and this among them, narrowing the difference of the eastern provinces is key; At the same time, the need to pay attention to, the big four plates differences in the development of banking is expanding gradually, in the process of promoting the coordinated development of regional banking need to cause enough attention. Second, in the process of promoting the coordinated development of the securities industry in our country, of the securities market, especially the regulation of the stock market should be a top priority. Finally, to coordinate regional development of insurance industry in our country, narrowing the regional differences, the eastern region is the key, and in the western region should cause enough attention .According to the results of the analysis, the differences of regional financial development in China is to be kept in a reasonable scope, promote the coordinated development of regional finance, this paper puts forward the following Suggestions:

\section{A. In Terms of Government Policy, Aimed at Narrowing the Difference of Regional Policy Should Fully Consider the Issue of Fairness and Efficiency}

In promoting the development of less developed areas faster at the same time, the developed area also cannot be ignored. In the process of narrowing the difference of region, equity and efficiency is not a contradiction, can be both.. Therefore, it is necessary to do more beneficial for less developed areas of regional economic policies and preferential fiscal, tax, monetary policy, promote the region to establish and perfect the financial system; Frame for developed areas continue to implement policies, and pay attention to in the implementation of the policy effect, at the same time pushing developed region to undeveloped region resources orderly diffusion. In addition, still should reduce the unnecessary intervention in the financial development, the financial industry, promote orderly market operation.

B. To Establish and Perfect the Reasonable Interregional Coordinated Development Mechanism, Financial Promote Regional Cooperation of the Government, to Break The Current to Operate According to Administrative Divisions, Regional Policy Barriers, Interregional Flow of Financial Resources Is Not More Smooth, Thus to Build a More Efficient Capital Operation System

The establishment of the mechanism can not only rely on a certain area or certain regional simple horizontal cooperation, and should set up a more systematic and joint mechanism. Can consider from the national level, therefore, set up regional financial services office, for different countries and regions to provide a platform of sharing resources of financial information, and promote the rational flow of financial resources in the area between.

\section{Differentiation of Financial Management Policy}

Due to uneven regional economic development in China, if a "one-size-fits-all" monetary policy inevitably leads to regional financial imbalances. Our government will prepare appropriate practice in the United States, often consider when making the legal deposit reserve rate differences between regions for discriminating reserve system.

\section{Encourage Financial Innovation}

In order to make up for the cause of reform and openingup in the central and western regions financial backward status quo, the government can draw lessons from the beginning of the reform in the eastern way to set up a special economic zone, in the western economic condition better environment is relatively stable cities set up financial reform test area, or in the financial development and innovation to tilt. Moderately relaxed Midwest financial industry market access threshold, encourage financial institutions for financial instruments in the Midwest and mixed management in financial business innovation, exploring the open.

\section{E. The Development of Regional Capital Market, to Strengthen Regional Financial Cooperation}

To strengthen regional financial cooperation is to promote balanced development of the financial and the important means of balanced development of regional economy, especially under the condition of the economic situation is not optimistic; its effect is more obvious. 
F. Establish and Improve the Financial Legal System, Especially for the Existing Laws and Regulations of Financial Supervision, Integration Must be Coordinated.

According to relative to the economy of the advanced financial development, financial development level can be for some higher area for the appropriate legislation in advance.

\section{G. Build a Contingent of High-Caliber People's Financial Awareness, Financial Personnel, This Is the Key to Improve the Regional Financial Competitiveness}

The improvement of people's financial awareness need to set up the correct financial concept, and encourage private financial development is the important way. High-quality financial personnel need a good social environment, on the one hand, establish professional personnel training, management mechanism, a targeted training to the employees, form the evolution mechanism of the candidates; Parts, on the other hand, also can pass some preferential policies to attract more foreign talent to work in the financial industry in our region.

\section{H. Will Tell from the Financial Industry's Own Development, to Ensure That the Regional Financial Health, Must Have a Good Running Environment}

First of all, a good social credit environment is the precondition of financial orderly operation, smooth running of the regional finance must be adapted to the regional credit system. Secondly, constructing the multi-level regional financial markets, mainly on the capital market, the steady development of money market, insurance market and the futures market. It also need to encourage some conditional area to develop the regional financial derivatives market. It is an inevitable choice for Chinese financial development, and it must play the role of local government and related financial sector, which can provide a good environment for financial innovation and motivation. Finally, regional financial cooperation is the guarantee of regional financial industry keeping long-term effective development, the level of local government must give up to regional interests, performance as the ultimate goal of traditional thinking, in the long run result in different parts of the financial cooperation, on the basis of bringing in foreign capital, promote financial resources reasonable flow region, can drive regional financial eventually establish a sustainable development of regional financial center.

In short, narrow the gap between regional finance in China is a gradual and long process, it has to do with the geographic, historical, economic development level, the national macroeconomic policy, people's ideological consciousness, etc. all have inseparable relationship. From the perspective of the cause of regional financial differentiation, the cause of the financial differences is diverse, and both of history, there is also a political, institutional, cultural, environmental and other factors, we cannot completely eliminate the differences, in fact moderate financial gap for promoting regional competition is also good, we can control the financial gap to a certain level, policymakers in formulating the related financial policy, not only focus on their own conditions for economic development, but also with open eyes and mind, sufficient use and analysis of location advantage, economic development, spatial dependence, and financial cooperation and other geographical conditions, strengthening regional exchanges, play the role of the regional financial center, expand the scope of financial diffusion and intensity, narrow the gap of regional financial development, eventually realize the sustainable development of the financial sector.

\section{REFERENCES}

[1] Comprehensive development institute (shenzhen), China. The 7th China financial centres index (CDI CFCI 7), China's financial center, information network, September 24, 2015.

[2] Liu Yiwen zong-yi hu. Regional financial resources difference influence on economic development $[\mathrm{J}]$. Journal of economic geography, 2010 (4) : 625-628.

[3] The people's bank of China. "in 2014 China's regional financial operation report", July 3, 2015.

[4] Wang Jingwu. Financial development and economic growth: the empirical analysis based on China's regional financial development [J]. Journal of finance and economy, 2005 (10) : 23-26.

[5] Wen-jing wang. The securities brokerage business marketing strategy study [J]. Journal of enterprise technology development, 2015 (8) : 125-126.

[6] Xiaoxiao Chen. Performance [C] in different development of regional finance in China, the capital economic and trade university master degree thesis, March 2013.

[7] Zhang Futian. Regional finance deepening and the size of government's influence on economic growth $[\mathrm{J}]$. Journal of modern economy, 2014, (4) : 56-60.

[8] Guo Yedong. Regional financial development difference and its reason analysis [C], Ph.D. Dissertation, capital university of economics and business, in October 2010. 